\title{
UMA PROPOSTA METODOLÓGICA: programas educativos e princípios de análise
}

\section{A methodologic proposal: educative programs and principles of analysis}

\author{
Rosangela G. de Oliveira ${ }^{a}$, Tânia Luiza Bonassa ${ }^{b}$ \\ ${ }^{a}$ Professora de Arte da Rede Estadual do Paraná e atualmente compõe o Núcleo de Análise de programas e Programação da TV \\ Paulo Freire da Secretaria de Estado da Educação do Paraná, Mestranda em Educação da UFPR (Universidade Federal do Paraná), \\ Curitiba, PR - Brasil, e-mail: rhogoncalves@gmail.com

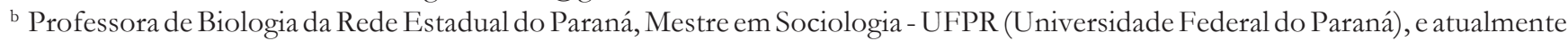 \\ compõe o Núcleo de Análise de Programas e Programação da TV Paulo Freire da Secretaria de Estado da Educação do Paraná, \\ Curitiba, PR - Brasil, e-mail: taniabonassa@seed.pr.gov.br; taniabonassa@yahoo.com.br
}

\begin{abstract}
Resumo
A composição da grade da programação da TV Paulo Freire - emissora vinculada à Secretaria de Estado de Educação do Paraná - baseia-se em critérios e princípios que têm na escola um importante referencial. Essa composição tem como uma das etapas a análise e/ou seleção de programas e para tal sistematizaram-se critérios e princípios. Este artigo pretende explicitar esses critérios e, na medida em que torna relevante a experiência docente na educação básica, estabelecer relações com concepções significantes de sujeitos do espaço escolar, cotidiano escolar, televisão e cultura. Os sujeitos que estão no universo escolar mantêm uma complexa relação com o saber e com a cultura do qual a televisão é parte. O currículo, ao mediar as relações sociais e, portanto, culturais na escola, deve ser dinâmico, de forma a incorporar as relações e processos de leitura de outros textos não-escritos, ou seja, textos televisionados. Dessa forma, desenvolveu-se uma metodologia própria de análise e valoração para escolha e/ou seleção de programas educativos, tendo em vista que a composição da grade relaciona-se ao fazer pedagógico. Concebemos nossas escolhas de programas com um potencial de uso didático que ao ser povoado de conteúdos escolares, é provocador de pesquisa.
\end{abstract}

Palavras-chave: Educação; Televisão; Análise de programas educativos. 


\begin{abstract}
The composition of the grating of the programming of the TV Paulo Freire - Secretaria de Estado da Educação do Paraná (State Secretary of Education of the Paraná) - is based on criteria and principles that have in the school an important referential. This composition has as the one of the stages analysis and/or election of programs and for such criteria and principles had been systemized. This article intends to explain these criteria and, in the measure where it becomes relevant the teaching experience in the education, to establish relations with significant conceptions of subjects of the school, everyday school life, television and culture. It was developed a proper methodology of analysis and valuation for choice and/or election of educative programs. We conceive our choices of programs with a potential of didactic.
\end{abstract}

Keywords: Education; Television; Analysis of educative programs.

\section{INTRODUÇÃO}

Ao recebermos o convite para compor a equipe da emissora de televisão Paulo Freire vinculada à Secretaria de Estado da Educação do Paraná - para, inicialmente, contribuir na sua concepção inicial, deparamo-nos com o desafio de aliar a nossa experiência - professoras da Educação Básica - com uma tecnologia, embora tão familiar, desconhecida no seu aspecto mais formal e teórico.

Ao compormos o Núcleo de Programação da referida TV, tivemos como uma das atribuições a análise de programas ${ }^{1}$ para a composição da grade da programação, logo, o desafio foi - e ainda é - pensar como nossa experiência na escola poderia contribuir para a concepção de critérios e princípios da escolha de uma programação com potencial educativo e para a composição da grade, tendo em vista o público-alvo que caracteriza esta $\mathrm{TV}^{2}$ a comunidade escolar da Rede Estadual de Educação do Paraná.

Acreditamos que a televisão é um meio que permite aprendizagens diversas e estar no processo do "fazer" televisivo exige - além das leituras no contexto teórico produzido em tecnologias, comunicação e educação - pensar esse meio incorporado às práticas escolares. Ou seja, esse trabalho exige o esforço de conjugar as teorias pertinentes e nossas concepções de escola.
$\mathrm{Na}$ busca de referenciais teóricos e/ou relatos de experiências, deparamo-nos com a escassez de trabalhos que discutem critérios propriamente ditos na análise de programas, embora soubéssemos de antemão que os critérios para escolha de programas seriam, de certa forma, produzidos por nós, tendo em vista a especificidade do público-alvo e suas necessidades.

Pretendemos, com esse texto, na medida em que relatamos nossa experiência, sistematizar os princípios que adotamos tanto na análise de programas educativos, quanto na composição da grade de uma programação com caráter educativo.

\section{ESCOLA E TELEVISÃO NA ESCOLA}

Quando pensamos na escola, é fundamental pensar nos sujeitos que ocupam o espaço escolar (alunos, professores, funcionários, pais e/ou responsáveis) e, conseqüentemente, é necessário desvelar o que entendemos por sujeitos, cotidiano escolar, cultura e currículo.

Sujeitos são aqueles que produzem cultura, que transformam e transformam-se nas relações sociais, que interpretam como Charlot (2000) nos explica abaixo, a partir de suas subjetividades e concretudes. Reconhecer que estes sujeitos, antes de assumirem seus papéis no espaço escolar - como alunos, professores, funcionários, pais e/ou responsáveis - são

\footnotetext{
1 Análise e seleção de programas televisivos de produção própria e análise de programas das emissoras parceiras.

2 A TV Paulo freire é uma televisão pública criada e vinculada pela Secretaria de Estado da Educação do Estado do Paraná e que possui como fim transmitir uma programação, própria e de parceiras, direcionada as 2.100 escolas da rede pública.
} 
também: crianças, jovens, adultos, idosos, indígenas, mulheres, homens, trabalhadores, do campo, da cidade, enfim, existem enquanto indivíduos em seus múltiplos papéis sociais.

Portanto, optamos por conceituar o sujeito plural a partir da sua relação com o saber, e para isso utilizamos a definição de Charlot (2000), porém antes cabe usar o mesmo autor e sua consideração sobre "relação com o saber"

A noção de "relação com o saber", tal como foi construída e depois desenvolvida na literatura psicológica, sociológica e pedagógica ocidental [...] pressupõe a existência de um sujeito que constrói uma relação específica e pessoal com o conhecimento que lhe é proposto pela escola. A relação mais geral com a escola e com o aprender (CHARLOT, 1997) pressupõe igualmente a existência de um sujeito ao mesmo tempo específico e diferente dos outros sujeitos aprendizes por sua história pessoal, seus desejos e seu projeto pessoal. (CHARLOT, 2001, p. 115-116).

Agora sim podemos conceituar sujeito.

Um sujeito é:

- um ser humano, aberto ao mundo que não se reduz ao aqui e agora, portador de desejos movidos por esses desejos, em relação com os outros seres humanos, eles também sujeitos;

- um ser social, que nasce e cresce em uma família (ou em um substituto da família), que ocupa uma posição em um espaço social, que está inscrito em relações sociais;

- um ser singular, exemplar único da espécie humana, que tem uma história, interpreta o mundo, dá um sentido a esse mundo, à posição que ocupa nele, às suas relações com os outros, à sua própria história, à sua singularidade.

Esse sujeito:

- age no e sobre o mundo;

- encontra a questão do saber como necessidade de aprender e como presença no mundo de objetos, de pessoas e de lugares portadores de saber;

- se produz ele mesmo, e é produzido, através da educação. (CHARLOT, 2001, p. 33).

Estes sujeitos no espaço escolar produzem uma cultura específica a eles, com tempos próprios (cognitivos, subjetivos e concretos), organizam os conhecimentos e os saberes dentro de uma lógica - a escolar - que objetiva um aprendizado. O processo escolar compõe suas relações de saber na direção da didatização dos conhecimentos e que são concretizadas em um currículo.

Entendemos que a escola possui um cotidiano próprio, um cotidiano escolar, constituindo-se como um espaço plural, mediado de tensões, ou seja, heterogêneo. Por isso hoje só é possível pensar em uma escola com sujeitos.

E esses sujeitos, conforme afirmamos, produzem cultura. O conceito de cultura em Williams (1969) é amplo e pertinente aqui. Para Williams (1969), cultura é o resultado de toda experiência humana tanto do cotidiano quanto nos meios de produção, nas formas como as pessoas se expressam e como se relacionam.

Também consideramos as três categorias de cultura definidas por Williams (2003): “[...] la 'ideal'; [...] la 'documental', e [...] la definición 'social' de la cultura, para la cual ésta es la descripción de un modo determinado de vida, que expresa ciertos significados y valores no sólo en el arte y el aprendizaje sino también en instituiciones y el comportamiento ordinario." (WILLIAMS, 2003, p. 50). Ou seja, a cultura está presente nas relações, nos bens materiais e imateriais, nos movimentos de tensão e imposição de determinados símbolos e comportamentos e, portanto, nos saberes e práticas escolares.

Nesta escola tensionada, antagônica, plural - justamente por estar constituída por diversos sujeitos - quando procura se entender, entender a sociedade e, ao mesmo tempo, entender-se na sociedade, é inevitável que se depare com desafios próprios da contemporaneidade, os de incorporar e legitimar novas possibilidades pedagógicas trazidas pelos sujeitos e pelas interações com as tecnologias presentes na sociedade. 
Olhar para estas possibilidades, presentes para além das fronteiras de seus pátios e muros, requer refletir o currículo - em uma de suas funções: mediador nas relações de saber - os sujeitos do espaço escolar e as culturas. Essa reflexão pressupõe pensar as práticas de um currículo amplo e dinâmico, não composto apenas por um rol de conteúdos programáticos pertencente a cada disciplina, mas o reverso desta perspectiva, visualizando seus conteúdos na dinâmica dos acontecimentos sociais, na sua interferência como escola na sociedade e da interferência da sociedade nas dinâmicas da escola. Nesta perspectiva, Silva (2004), ao analisar diferentes teóricos do currículo, traz uma importante provocação:

\begin{abstract}
Depois das teorias críticas e pós-críticas do currículo torna-se impossível pensar o currículo simplesmente através de conhecimentos técnicos como os de ensino e eficiência ou de categorias psicológicas como as de aprendizagem e desenvolvimento ou ainda de imagens estáticas como as da grade curricular e lista de conteúdos. Num cenário pós-crítico, o currículo pode ser todas essas coisas, pois ele é também aquilo que dele se faz, mas nossa imaginação está agora livre para pensá-lo através de outras metáforas, para concebê-lo de outras formas, para vê-lo de perspectivas que não se restringem àquelas que nos foram legadas pelas estreitas categorias da tradição. (SILVA, 2004, p. 147).
\end{abstract}

E este espaço escolar pleno de sujeitos e suas culturas está inegavelmente marcado pela presença dos meios de comunicação, principalmente da televisão.

As pesquisas mostram que a televisão faz parte da vida dos brasileiros ${ }^{3}$ e com mais ou menos intensidade, da vida dos alunos, professores, funcionários e pais e/ou responsáveis, portanto, do cotidiano escolar. Em decorrência disso, entendese, como pressuposto básico, que a televisão é um veículo de aprendizagens diversas e apresenta-se assim porque ela é um dispositivo audiovisual que expressa a forma de pensar do homem e também exerce influência sobre esta forma de pensar, em outras palavras, insere-se na cultura.

Fischer (2003, p. 18) chama a atenção para o fato de que "a presença da TV na vida cotidiana tem importantes repercussões nas práticas escolares, na medida em que crianças, jovens e adultos de todas as camadas sociais aprendem modos de ser e estar no mundo [...] nesse espaço de cultura." Afirma, ainda, que a TV seria um lugar privilegiado para aprendizagens: "aprende-se com ela desde formas de olhar e tratar nosso próprio corpo até modos de estabelecer e compreender diferenças de gênero [...] diferenças políticas, econômicas, étnicas, sociais, geracionais" (FISCHER, 2003, p. 16).

Não pretendemos esgotar as discussões conceituais de sujeito, cultura, cotidiano escolar e currículo apenas apontar alguns marcos que nos orientam nesta empreita. Estas bases conceituais de sujeitos, cultura e cotidiano escolar sustentam nossas propostas de valoração e categorização didáticas e estéticas de programas televisivos e educativos, porque esta é uma televisão voltada para a escola, seus sujeitos e suas práticas pedagógicas.

Nosso público espectador é também parceiro, pois parte da programação é produzida a partir das ações da escola. Faz parte da nossa compreensão neste processo de escolha de programas que a escola também se reconheça nesta programação. É, sobretudo, uma TV pensada para a escola, com a escola, evitando ao máximo a arrogância e a presunção de ensinar a escola a sua função, mas de refletir com a escola outras possibilidades pedagógicas. Porém, de forma alguma entendemos que os produtos televisivos que não atendem ao conjunto de qualificações por nós apontados possam ser menos educativos, há alguns programas que possuem outra proposta de sociedade, educação e sujeito diferente daquela que nos embasa.

Dessa forma, é importante que a escola incorpore a televisão e sua programação como fonte de pesquisa, ou seja, ela não é simplesmente

\footnotetext{
No total das moradias do país, 87,4\% tinham geladeira, 34,5\% contavam com máquina de lavar roupa. A televisão existia em 90,3\% dos domicílios e o rádio, em 87,8\%, enquanto o microcomputador estava disponível em 16,3\% das residências. (IBGEPesquisa Nacional por Amostra de Domicílios - PNAD 2004. Condições da habitação e posse de bens duráveis).
}

Rev. Estud. Comun., Curitiba, v. 9, n. 18, p. 19-26, jan./abr. 2008 
um mero recurso audiovisual para "enriquecer" a aula, é mais que isso: é um meio que permite leitura, reflexão e interpretação tanto de sua linguagem (programas) como pelo próprio veículo, ampliando, dessa forma, as leituras e as interpretações da realidade em que vivemos.

\section{CRITÉRIOS E CONCEITOS NA ANÁLISE DE PROGRAMAS}

Pensar a televisão incorporada ao cotidiano escolar e inserida como fonte de pesquisa de forma efetiva no processo ensino-aprendizagem pressupõe ver/ler nos programas os seus potenciais educativos. E para tal são necessários conceitos e critérios que possibilitem essa interpretação, sendo que a concepção dos critérios tem como um dos referenciais o público alvo da TV Paulo Freire.

Esta concepção de critérios e princípios exigiu a busca de fontes que tratassem desta temática, pois conforme afirmamos, embora tão familiar, a TV era nossa desconhecida.

Há muitos trabalhos, por exemplo, que levantam princípios de análise numa perspectiva ampla do que representa esse meio de comunicação social. Porém, há uma escassez de trabalhos que apresentam e discutem critérios e princípios de análise de programas educativos tomados em si.

Conforme Machado (2005), "a idéia disseminada é que a televisão é um 'serviço', sistema de difusão, fluxo de programação [...]. Segundo essa concepção, o que importa não é o que acontece de fato na tela, mas o sistema político, econômico e tecnológico no qual se forjam as regras de produção e as condições de recepção.” (MACHADO, 2005, p. 16). Embora o autor saliente que não há nada de errado com estas abordagens, a questão é que o foco não se volta para o conjunto de trabalhos audiovisuais que a televisão produz, ou seja, os programas.

Analisar e valorar programas, sob uma perspectiva pedagógica, não é tarefa fácil. Todos os programas podem possibilitar aprendizagens diversas, não existe programação neutra. Por essa razão, sistematizamos critérios que nos orientam na análise e escolha de programas voltados para o público em questão. Todos os aspectos envolvidos na construção do programa ensinam e o fazem de forma complexa, uma vez que as imagens fazem parte de um ecossistema comunicativo (MARTINBARBERO; REY, 2001).

Dito isto, descreveremos a seguir os critérios e princípios com os quais analisamos desde como "olhamos" os programas à formatação estética e pedagógica - tanto os de produção própria, como os das parceiras.

Cabe, inicialmente, com o objetivo de dar clareza ao texto, salientar a importância do conceito qualidade na televisão, pois, aqui, significa qualidade da programação. Para se discutir e pensar qualidade na televisão é necessário conceituá-la, embora Machado (2005) nos chama a atenção para a complexidade do tema: "a qualidade em televisão está longe de ser uma matéria de consenso." (MACHADO, 2005, p. 23). Pela sua complexidade, acreditamos que, na medida em que descrevemos os princípios de análise de programas, estamos direta ou indiretamente afirmando se o programa é de qualidade.

A análise de um programa pressupõe observar em separado todos os seus elementos. Conforme afirmam Vanoye; Goliot-Lété (1994), na obra Ensaio sobre a análise filmica - embora falem sobre o filme, cabe em nosso caso - podemos "decompô-lo em seus elementos constitutivos. Despedaçar, descosturar, desunir, extrair, separar, destacar e denominar materiais que não se percebem isoladamente 'a olho nu', pois se é tomado pela totalidade. [A análise consiste] em estabelecer elos entre esses elementos isolados, em compreender em como eles se associam e se tornam cúmplices para fazer surgir um todo significante." Portanto, os elementos de análise descritos a seguir são "vistos" isoladamente, porém são constituintes importantes do produto e do processo do "fazer" televisivo.

Outra dificuldade de sistematizar os critérios - além da escassez de textos, conforme citado - está no fato de que lidamos com conceitos subjetivos, porém, na tentativa de conceituar qualidade e tendo em vista que os programas possam ser fontes de pesquisa optamos por exemplificar, quando possível, os seguintes princípios: ${ }^{4}$ qualidade técnica, contexto, diversidade de formato e conteúdo.

\footnotetext{
${ }^{4}$ Conforme explicitamos no início deste texto, não é nossa intenção aprofundarmos teorias sobre técnicas do fazer televisivo, principalmente sobre a imagem. Há inúmeros teóricos que se aprofundam sobre esse aspecto. Por exemplo, o texto A imagem de AUMONT (1993).
} 
1. Qualidade técnica: Um programa com potencial pedagógico deve propiciar aos espectadores acesso às informações veiculadas, para isso levase em conta a heterogeneidade do público-alvo e a distribuição espacial de uma sala de aula: ${ }^{5}$

a) gerador de caracteres $(G C)$ : os espectadores lêem de forma diversa: uns lêem com mais agilidade, outros de forma mais lenta, portanto, o tipo de fonte e o tamanho dessa fonte são considerados. Por exemplo, num programa que tem como recurso o lettering, este deve ser lido com clareza por todos;

b) áudio: além do fato de que os espectadores ouvem de forma diversa, é importante considerar que a qualidade técnica do áudio deve ter uma variação dinâmica pequena dentro do padrão (escala de volume) utilizado em televisão. Deve ser livre de ruído, ou ter o ruído minimizado, ou seja, o volume do áudio e sua qualidade devem contribuir para que o espectador compreenda o que está ouvindo. Por exemplo, um programa de entrevista é fundamental ouvir o entrevistado, assim como numa cena externa no centro de uma cidade, os ruídos do trânsito não podem ser um fator que impeça a compreensão do contexto;

c) imagem: assim como os aspectos salientados acima, a imagem deve manter coerência com o proposta de formato do programa e contribuir para que o espectador compreenda o que está "vendo". Por exemplo: um programa de entrevista em estúdio, entrevistador e entrevistados devem estar iluminados com equilíbrio entre luz e sombra. A luz utilizada deve convidar o espectador a ouvir, já que numa entrevista as idéias é que são protagonistas. A iluminação, aqui, não pode ser um elemento de dispersão do espectador.
Enfim, é necessário ter qualidade técnica para ser pedagógico, ou seja, é preciso que se ouça, se vejam as imagens e se leiam os textos. Embora, sabe-se, que o ruído proposital ou uma concepção estética diferenciada de iluminação, etc. possam ser pertinentes e, também, educativos.

2. Contexto: uma característica importante de um programa com potencial pedagógico é situar o espectador, além da relação espaço/ tempo, revelar as relações sociais e culturais contidas na realidade mostrada pelos sujeitos, ou seja, falamos de sujeitos inseridos numa realidade complexa. A medida que o programa contextualiza o sujeito, sua identidade é revelada e tem-se: quem fala, o que fala, por que fala, de onde fala e como fala. Por exemplo: Num documentário não é apenas a localização geográfica e temporal do indivíduo que dará o contexto, é mais que isso: são as relações que o constituem como sujeito naquele espaço social, mais ou menos explicitadas.

3. Diversidade de formato: formatos diversos ampliam o acesso e a experiência estética a uma pluralidade de linguagens que estão associadas à dinâmica do programas.

4. Conteúdo: a preocupação inicial é que os conceitos desenvolvidos nos programas estejam em consonância com as políticas educacionais do Estado. Por exemplo, um depoimento de um adulto em processo de alfabetização não pode ter um quadro-negro como cenário com a frase: "A vaca Vavá viu a vassoura." Mas é adequado se a mesma cena apresenta como cenário um quadro-negro com os nomes dos alfabetizandos, ou um pequeno texto contando a história desses nomes.

Todos os elementos que constituem um programa podem ser elementos instigadores de reflexão: a qualidade técnica, o contexto, o conteúdo e o formato. Constituem-se em fontes de pesquisa para o professor considerados isoladamente ou em seu conjunto. Cabe ao professor assistir ao programa, analisá-lo em seu potencial e, quando possível, incorporá-lo ao seu planejamento.

\footnotetext{
$5 \mathrm{Na}$ distribuição dos alunos em uma sala alguns estão mais próximos do aparelho de TV e outros mais distantes.
} 


\section{COMPOSIÇÃO DA GRADE DA PROGRAMAÇÃO}

A construção da grade requer algumas considerações pensadas a partir do cotidiano escolar. Conforme afirmado anteriormente, sabemos que os elementos que compõem este cotidiano são complexos e múltiplos porque são as múltiplas realidades dos sujeitos compartilhadas em um espaço determinado e em um tempo determinado, ou seja, como nos fala Rockwell; Ezpeleta (1985), são as "formas de existência material da escola" (ROCKWELL; EZPELETA,1985, p. 115).

Sabemos que a grade de programação deve ser dinâmica, pois o público já está familiarizado com uma seqüência de programas não-linear, ou seja, programas de formatos diversos, tempos e abordagens distintas, que sugerem um determinado ritmo, instituído por grandes redes de televisão no Brasil. Entendemos também que é possível romper sutilmente com esta lógica rítmica, ofertando programas que exigem um olhar mais atento e cuidadoso, um tempo mais moroso para sua apreensão. observados:

Dito isto, os seguintes aspectos são

- Público-alvo: devem estar contemplados programas específicos para professores, para alunos, para a comunidade, para funcionários.

\section{- Tempo físico:}

a) a programação é pensada para ser exibida tendo em vista o período diário de funcionamento da escola e a programação exibida pela manhã, repete-se à tarde e à noite;

b) a duração da aula e intervalos nos turnos, por exemplo, o telejornal "Extraclasse", de produção própria, está programado para ir ao ar no intervalo do turno (recreio da escola) por ser um programa dirigido aos professores;

c) o calendário escolar também é um aspecto a ser observado: férias, semanas pedagógicas e os 200 dias letivos obrigatórios;

d) a reapresentação de programas em dias e horários alternativos possibilita a ampliação do acesso pela comunidade escolar.
- Tempo e formato de programas: $O$ fluxo de programação deve contemplar programas longos, mais densos e também programas curtos, leves e líricos ou curtos e densos, enfim, mesclamos programas de formatos diversos de forma a garantir um movimento na grade, o qual pode ser um referencial de identidade;

- Identidade da TV: sabemos que a identidade da TV não está relacionada somente com a dinâmica da grade, mas também, por exemplo, com as concepções da própria política que institui a TV. Além dos programas de produção própria, programetes e vinhetas inseridos ao longo da programação "marcam" para o público espectador a concepção educativa/pedagógica da televisão e articulam a sua identidade.

Entendemos que uma política midiática pública é aquela que possibilita efetivamente a incorporação da televisão e sua linguagem pela escola. O que significa ações que permitam o acesso, e, principalmente, o intenso investimento em formação continuada, dos professores e gestores. Embora a linguagem televisiva seja familiar, isto não é garantia de que ela seja incorporada no processo de ensino aprendizagem.

Portanto uma política midiática pública deve dialogar com a escola e a comunidade escolar. Uma possibilidade para estabelecer este diálogo com a comunidade escolar no uso freqüente de pesquisas qualitativas e quantitativas que dariam aos gestores públicos um feedback, ou seja, elementos para reflexão sobre as próprias concepções, seus objetivos, metas, práticas e a reestruturação do processo de incorporação da televisão no cotidiano escolar como uma aliada.

\section{REFERÊNCIAS}

AUMONT, J. A imagem. Tradução de Estela dos Santos Abreu. Campinas: Papirus, 1993.

CHARLOT, B. Da relação com o saber. Porto Alegre: Artmed, 2000.

Os jovens e o saber: perspectivas mundiais. Porto Alegre: Artmed, 2001. 
FISCHER, R. M. B. Televisão \& educação: fruir e pensar a TV. 2. ed. Belo Horizonte, Autêntica, 2003.

MACHADO, A. A televisão levada a sério. 4. ed. São Paulo: SENAC São Paulo, 2005.

MARTIN-BARBERO, J.; REY, G. Os exercícios do ver: hegemonia audiovisual e ficção televisiva. São Paulo: SENAC, 2001.

ROCKWELL, E.; EZPELETA, J. A construção social da escola. Revista Brasileira de Estudos Pedagógicos, Brasília, v. 66, n. 152, p. 106-119, jan./abr. 1985.

SILVA, T. T. Documentos de identidade: uma introdução às teorias do currículo. 2. ed. Porto Alegre: Artmed, 2004.

VANOYE, F.; GOLIOT-LÉTÉ, A. Ensaio sobre a análise fílmica. Campinas: Papirus, 1994.

WILLIAMS, R. Cultura e sociedade. São Paulo: Companhia Editora Nacional, 1969.

La larga revolución. Buenos Aires: Nueva Vision, 2003.

Recebido: 10/10/2007

Received: 10/10/2007

Aprovado: 03/12/2007

Approved: 12/03/2007 